\title{
Fourth-Generation Storage Rings
}

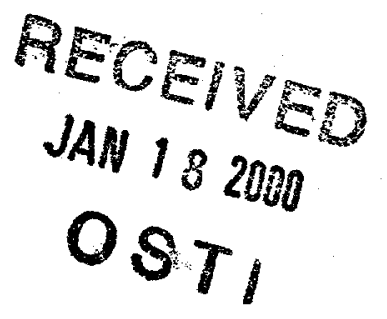

\author{
John N. Galayda \\ Advanced Photon Source, Argonne National Laboratory \\ INTRODUCTION
}

It seems clear that a linac-driven free-electron laser is the accepted prototype of a fourth-generation facility. This raises two questions: can a storage ring-based light source join the fourth generation? Has the storage ring evolved to its highest level of performance as a synchrotron light source? The answer to the second question is clearly "no." I think the answer to the first question is unimportant. While the concept of "generations" has been useful in motivating thought and effort towards new light source concepts, the variety of light sources and their performance characteristics can no longer be usefully summed up by assignment of a "generation" number.

\section{THREE ALTERNATIVE DEFINITIONS OF A FOURTH- GENERATION LIGHT SOURCE}

An organized search for the most important directions in which to expand the performance of existing or new synchrotron radiation facities was the goal of the 1992 SLAC Workshop on Fourth-Generation Light Sources (1). In his charge to the workshop, Herman Winick suggested that "....any device which has one or more features (e.g., brightness, coherence, peak power, shortness of pulse) which exceeds the performance level of sources now in operation or construction by an order of magnitude or more" could be considered a member of the fourth generation.

The 10th ICFA Beam Dynamics Workshop, held in Grenoble in 1996 (2), produced a second, more specific working definition of a fourth -generation source, based on the characteristics of the light output. Indeed the definition was so specific and compelling as to motivate serious consideration of a SASE FEL as the "next generation" by the community of $\mathrm{x}$-ray experimenters. The group addressing scientific opportunities for hard x-ray sources was led by Jens Als-Nielsen (3), and the working group addressing scientific opportunities for soft $\mathrm{x}$-ray/VUV sources was led by Ingolf Lindau (4). Both groups reported that the ideal fourth-generation source would produce very short pulses of radiation, of the order of 100 femtoseconds. Both groups also identified diffraction-limited source emittance as highly desirable. The hard $\mathrm{x}$-ray group added that the ideal facility would have much higher peak and average brightness than third-generation sources and provision for at least $30 \mathrm{x}$-ray beamlines. 


\section{DISCLAIMER}

This report was prepared as an account of work sponsored by an agency of the United States Government. Neither the United States Government nor any agency thereof, nor any of their employees, make any warranty, express or implied, or assumes any legal liability or responsibility for the accuracy, completeness, or usefulness of any information, apparatus, product, or process disclosed, or represents that its use would not infringe privately owned rights. Reference herein to any specific commercial product, process, or service by trade name, trademark, manufacturer, or otherwise does not necessarily constitute or imply its endorsement, recommendation, or favoring by the United States Government or any agency thereof. The views and opinions of authors expressed herein do not necessarily state or reflect those of the United States Government or any agency thereof. 


\section{DISCLAIMER}

Portions of this document may be illegible in electronic image products. Images are produced from the best available original document. 
It was recognized that a facility like the TESLA FEL could fulfill all these requirements, while 100 femtosecond pulses and brightness of $10^{32}$ seemed impossible to produce with a storage ring. Since that workshop, accelerator designers have wondered aloud whether the third-generation sources would be the last rings to be built.

The final definition of "fourth-generation rings" is operational or perhaps ontological. The next generation of rings must have the property of existence, therefore the next generation of rings is defined by what is being built. The proceedings of this conference describe a host of new facilities as well as major upgrades and performance improvements to brightness and pulse duration in existing rings by factors of 10 or 100 , resonating with the definition of generations proposed in 1992. There can be no choice but to accept this explosion in construction of new rings as the next "generation." Furthermore, it is not too difficult to look beyond these new facilities to ring designs with yet higher performance.

\section{IMPROVEMENTS IN UNDULATORS, CURRENT, AND EMITTANCES}

Utilization of the full range of magnet performance parameters serves to decouple the choice of ring energy from the desired spectral output. This can be done with superconducting bends (5) or with small-gap, short-period undulators (6). Superconducting magnet technology could make it possible to duplicate the spectrum and tuning range of the 6-8 GeV third-generation rings at lower energy and lower emittance, as will be illustrated later in this article.

Higher brightness can be obtained by use of very long undulators. The SPring- 8 facility will dedicate one of its 34-meter straight sections to a 25-meter insertion device (7). It is to be installed in the spring of 2000 . This device is expected to produce beam brightness of $8 \times 10^{20}$ photons/( $\left(\mathrm{sec} \mathrm{mm}^{2} \mathrm{mrad}^{2} 0.1 \% \mathrm{dp} / \mathrm{p}\right)$.

B-factories such as KEKB and PEP-II (8) demonstrate what currents might be attainable in a synchrotron radiation ring. The High Energy Ring, operating at $9 \mathrm{GeV}$, will store a 1-ampere beam. The 3-GeV Low Energy Ring is well on its way to storing 2 amperes. The Low Energy Ring incorporates four anti-damping wigglers capable of generating $210 \mathrm{~kW}$ of synchrotron light with a critical wavelength of $9 \mathrm{keV}$. To reach these currents, the PEP-II Collaboration developed innovative if cavities with strongly damped parasitic modes, 1.2-MW klystrons with greatly increased bandwidth, and highly sophisticated digital beam stabilizing systems. Accelerator R\&D on this scale, routine in the high-energy physics community, could yield equally dramatic improvements in light source performance.

What emittance is small enough? The answer depends on the wavelength of interest. The minimum or diffraction-limited emittance of a source of radiation producing photons with wavelength $\lambda$ is 


$$
\varepsilon_{t} \sim \frac{\lambda}{4 \pi}
$$

For 1-angstrom photons, this corresponds to $0.008 \mathrm{~nm}$-radians. There is little to be gained at this wavelength by further reduction of the electron beam size.

Assuming one starts with a "unit cell" of focusing magnets optimized for a synchrotron light ring, the damped emittance scales as

$$
\left.\varepsilon \sim(\text { Electron energy) })^{2} \text { (number of cells) }\right)^{-3} .
$$

Vertical emittance is generally written as a constant $\kappa$ multiplying the ideal horizontal emittance, since it results from coupling of horizontal oscillations into the vertical plain by magnet field errors and nonlinear focusing. Addition of large numbers of wiggler magnets can further reduce the emittance, perhaps by as much as a factor of 10 . Whether or not damping wigglers are used, the brightness $B$ of a storage ring is proportional to

$$
\mathrm{B} \sim(\text { Beam Current }) \kappa^{-1}(\varepsilon)^{-2} .
$$

These expressions suggest that the brightness of a storage ring light source will grow to infinity (or at least to the diffraction limit) if the ring energy is scaled down to zero. Simply extrapolating to much lower energies (15) does not yield the desired performance improvements. At sufficiently high current densities within a bunch, electrons in the beam undergo Coulomb scattering events. Large-angle events cause loss of electrons, shortening the beam lifetime. One can compensate for lifetime reduction by means of top-up operation (16). Small-angle multiple scattering can be sufficiently severe at low energies to overcome the radiation damping mechanism, thus preventing the beam shrinking to the desired emittance. The ring designer can combat this emittance blow-up by incorporating many wiggler magnets into the lattice, to enhance radiation damping. One can also add extra if cavities to lengthen the bunches and reduce the rate of collisions between the electrons. Despite the problems posed by intrabeam scattering, it is certainly reasonable to envision ringbased light sources 100-1000 times brighter than present facilities.

The commissioning goal for third-generation facilities such as ESRF was a brightness of about $10^{18}$ photons $/\left(\mathrm{sec} \mathrm{mm}^{2} \mathrm{mrad}^{2} 0.1 \% \mathrm{dp} / \mathrm{p}\right)$. The ESRF team has exceeded their initial goals by a factor of $100\left(10^{20}\right.$ for $14-\mathrm{keV}$ photons $)$ at $6 \mathrm{GeV}$ by combining improvements in current (to $200 \mathrm{~mA}$ ), emittance, and coupling. By reducing the electron energy from $6 \mathrm{GeV}$ to $4 \mathrm{GeV}$, they obtained an equivalent improvement to $0.8 \times 10^{20}$ with only $100 \mathrm{~mA}$ stored (9).

Three groups of accelerator designers have investigated a $2.2-\mathrm{km}$-circumference version of the Advanced Photon Source. Wrulich (10), Hofmann and Rivkin (11) considered an 80-cell version of the APS operating at $7 \mathrm{GeV}$. They found that an emittance of $0.1 \mathrm{~nm}$ and a brightness of nearly $10^{22}$ (at $100 \mathrm{~mA}$ ) was possible if 200 meters of damping wigglers could be installed. Borland, Emery, Filhol, and Ropert 
(12) considered a similar ring operating at $4 \mathrm{GeV}$. Of the 80 available straight sections in such a ring, about 30 would be left for other insertion devices after installation of damping wigglers. One could, however, shorten the dipole magnets of the APS to create new straight sections for damping wigglers. This would leave nearly all of the 80 straight sections available for $\mathrm{x}$-ray beamlines. Estimates of emittance, lifetime (13), and brightness (14) for a 2-Tesla, 2-cm period undulator indicate that a brightness of $10^{22}$ at $300 \mathrm{~mA}$ is possible with a beam lifetime over two hours and moderate blow-up (to $0.05 \mathrm{~nm}$-radian) from intrabeam scattering. Perhaps $10^{23}$ could be reached at "B-factory" currents in a $2.2-\mathrm{km}$ ring.

\section{MORE SPECULATIVE IDEAS}

Huang and Ruth (17) have investigated the theoretical limits on emittance of an electron beam producing synchrotron radiation. They found no limit other than the electron Compton wavelength. Going to extremes of focusing that might be produced by atomic- or molecular-scale structures, they found that quantization of the transverse oscillations suppress the transverse motion of electrons normally produced by quantum fluctuations in synchrotron radiation. They also investigated the use of laser light as a kind of damping wiggler in very compact, low-energy rings. They computed the brightness of Compton-scattered laser photons, treating the case of a $100-\mathrm{MeV}$ storage ring producing $200-\mathrm{keV}$ photons at a rate of $10^{20} / \mathrm{sec}$ and an $8-\mathrm{MeV}$ electron storage ring producing $10^{15}$ photons $/ \mathrm{sec}$ at $1.24 \mathrm{keV}$.

Storage ring FELs (18) offer average brightness of $10^{26}-10^{27}$ with full transverse and temporal coherence. Wavelengths down to $194 \mathrm{~nm}$ can be produced at present. Very high gain storage ring FELs are expected to produce harmonics at wavelengths of $50 \mathrm{~nm}$ or less.

Accelerator scientists at ESRF and Orsay (19) found that retuning storage ring lattices to manipulate the dependence of electron circulation period on momentum (the "momentum compaction") did not bring appreciable improvements in bunch length, momentum spread, or single-bunch current limit. Production of bright subpicosecond light pulses from a storage ring seemed to be impossible by means of judicious lattice design. However, laser energy modulation of bunches in the ALS ring (20) has successfully produced 100 -fs pulses of $10^{6}$ photons/sec. Litvenenko (21) has proposed that a $300-\mathrm{GHz}$ FEL could be used to power "inverse FEL" systems in a storage ring. In an inverse FEL, externally supplied laser light is the input power source that bunches and accelerates electrons. The process is essentially a timereversed FEL. He estimates that $8-\mathrm{MV}$ acceleration could be supplied in a $1-\mathrm{GeV}$ ring by inverse FELs to produce rather high current bunches with length about $200 \mathrm{fs}$.

Kulipanov, Skrinsky, and Vinokurov (22) have suggested that a 6-GeV microtron accelerator could serve as the basis of a synchrotron light source with average brightness comparable to SASE FELs. While the device is not a laser, it has very high average brightness and good coherence due to the small $(\sim 0.010 \mathrm{~nm}$-radian at $6 \mathrm{GeV})$ 


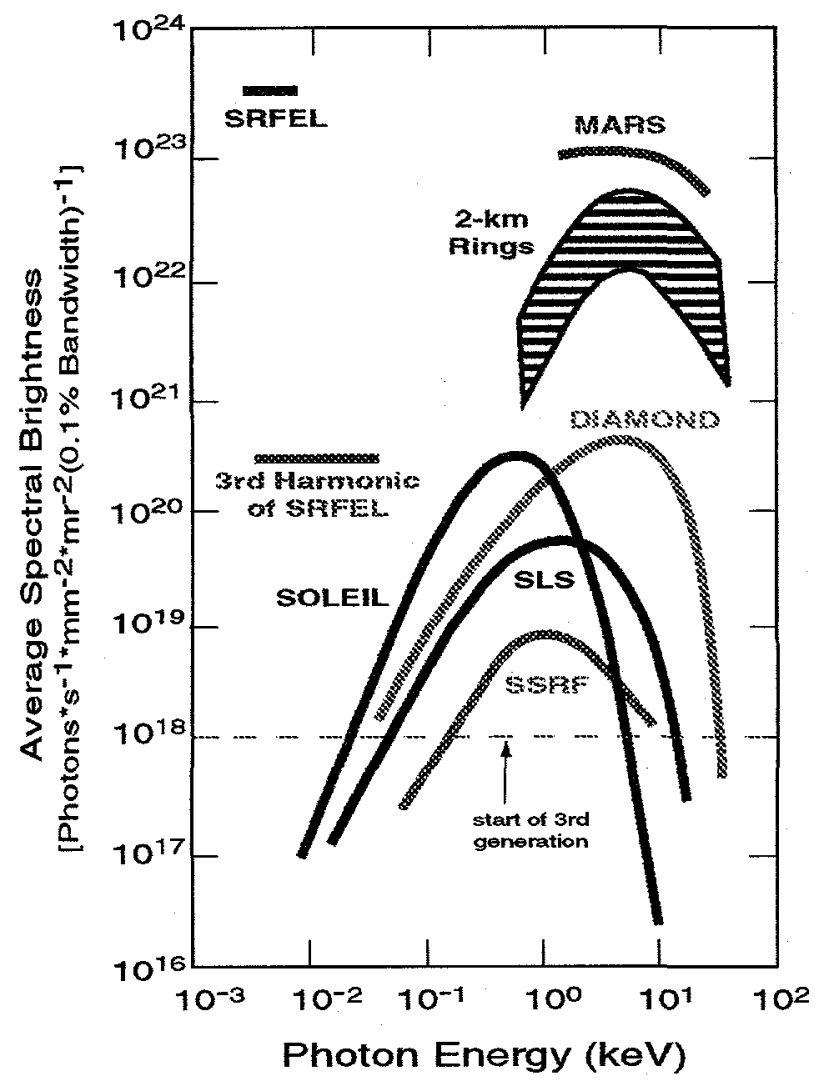

Brightness of some post-third-generation rings under construction. Possible spectral coverage of a 2-km version of the APS, and the MARS device is also shown.

emittance beam that a microtron can produce. While the device they propose (a "Multipass Accelerator-Recuperator Source," or MARS) is by no means small, it may be less expensive than an $\mathrm{X}$-ray free-electron laser.

\section{CONCLUSIONS}

There is significant potential for improving the performance of storage ring light sources to levels above $10^{22}$ in brightness, relative to the present operation of thirdgeneration rings. Extrapolations of present designs can be expected to have damping wigglers, short lifetime due to Touschek scattering, frequent or "top-up" injection, and lower electron beam energy than thirdgeneration ring sources of hard $\mathrm{x}$ rays.

Interesting work on laser cooling, microbunching, and SR-FELs could introduce new possibilities for ringbased light sources. One can expect accelerator $R \& D$ to create yet more possibilities. Ultimately, what is built is determined by $\mathrm{x}$-ray experimenters with foresight and energy.

\section{ACKNOWLEDGMENTS}

The author extends thanks to Michael Borland and Roger Dejus for computations of emittance and brightness of a alternative designs for a $2.2-\mathrm{km}$ version of the Advanced Photon Source. This work is supported by the U.S. Department of Energy, Office of Basic Energy Sciences, under Contract No. W-31-109-ENG-38.

\section{REFERENCES}

1. Cornacchia, M. and Winick, H., Eds., Workshop on Fourth Generation Light Sources, February 24-27, 1992, SSRL $92 / 02,1992$, p. 8. 
2. Laclare, J. L., Ed., 10th ICFA Beam Dynamics Panel Workshop - 4th Generation Light Sources, Grenoble, January 22-25, 1996, ESRF.

3. Ibid., pg 38 .

4. Ibid, pg. 25 .

5. Padmore, H., "Superconducting Bending Magnet Sources at the Advanced Light Source," these proceedings.

6. Krinsky, S., "In-vacuum Undulators and Mini-beta Straights," these proceedings.

7. Kamitsubo, H. and Kumagai, N., "Performance and New Capabilities of SPring-8," Proceedings of the 1999 Particle Accelerator Conference, New York, 1999, pp. 188-191.

8. Seeman, John, "Commissioning Results of the KEKB and PEP-II B-Factories," Proceedings of the 1999 Particle Accelerator Conference, New York, 1999, pp. 1-5.

9. Farvacque, L., Filhol, J.-M., Hardy, L., Jacob, J., Ropert, A., Weinrich, U., "Operating the ESRF at 4 GeV," Proceedings of the 17th ICFA Beam Dynamics Workshop, April 2-6, 1999, to be published.

10. Wrulich, A., "Future Directions in the Storage Ring Development for Light Sources," Proceedings of the 1999 Particle Accelerator Conference, New York, 1999, pp. 192-196.

11. Hofmann, A. and Rivkin, L., "Fourth Generation Storage Ring Sources," Synchrotron Radiation News, November 1999.

12. Borland, M., Emery, L., Filhol, J.-M., Ropert, A., "Sketch of a Future Storage Ring Light Source," Proceedings of the 17th ICFA Beam Dynamics Workshop, April 2-6, 1999, to be published.

13. Borland, M., private communication.

14. Dejus, R., private communication.

15. Laclare, J. L., Ropert, A., Weinrich, U., "ESRF Approach to Fourth Generation Light Sources," J. L. Laclare, Ed., 10th ICFA Beam Dynamics Panel Workshop - 4th Generation Light Sources, Grenoble, January 22-25, 1996, ESRF, pp. WG3-7 - WG3-10.

16. Emery, L., "Progress Toward Top-up Mode Operations at the Advanced Photon Source," these proceedings.

17. Huang, Z. and Ruth, R., "Radiative Cooling of Relativistic Electron Beams," Proceedings of the 1999 Particle Accelerator Conference, New York, 1999, pp. 262-266.

18. Johnson, E., "FEL's Getting Shorter: a Survey of VUV FEL Sources and Science," these proceedings; Litvenenko, V., "Ring-Based Sources Overview," Proceedings of the 17th ICFA Beam Dynamics Workshop, April 2-6, 1999, to be published; Walker, R., "Overview of Synchrotron Radiation and Free-Electron Laser Projects," Proceedings of the 1998 European Particle Accelerator Conference, Stockholm, pp. 133-137; Couprie, M. E., "FELs Using Storage Rings," Proceedings of the 1996 European Particle Accelerator Conference, Sitges (Barcelona), pp. 100-104.

19. Limborg, C., "A Review of Difficulties in Achieving Short Bunches in Storage Rings," Proceedings of the 1998 European Particle Accelerator Conference, Stockholm, pp. 151-155.

20. Zholentz, A. et al., "Development of a Source of Femtosecond X-ray Pulses Based on an Electron Storage Ring," Proceedings of the 1999 Particle Accelerator Conference, pp. 2370-2372.

21. Couprie, M. E., "Report of Working Group III: Ring-Based Sources," Proceedings of the 17th ICFA Beam Dynamics Workshop, April 2-6, 1999, to be published.

22. Kulipanov, G., Skrinsky, A. and Vinokurov, N., "MARS - A Project of the Diffraction-Limited Fourth Generation X-ray Source," Proceedings of the 17th ICFA Beam Dynamics Workshop, April 2-6, 1999, to be published. 